\title{
A Comparison of Anterior Cervical Discectomy and Fusion versus Fusion Combined with Artificial Disc Replacement for Treating 3-Level Cervical Spondylotic Disease
}

\author{
Seo-Ryang Jang, M.D., Sang-Bok Lee, M.D., Kyoung-Suok Cho, M.D., Ph.D. \\ Department of Neurosurgery, Uijeongbu St. Mary's Hospital, College of Medicine, The Catholic University, Uijeongbu, Korea
}

Objective : The purpose of this study is to evaluate the efficacy and safety of 3-level hybrid surgery (HS), which combines fusion and cervical disc replacement (CDR), compared to 3-level fusionin patient with cervical spondylosis involving 3 levels.

Methods : Patients in the anterior cervical discectomy and fusion (ACDF) group $(n=30)$ underwent 3-level fusion and the HS group $(n=19)$ underwent combined surgery with fusion and CDR. Clinical outcomes were evaluated using the visual analogue scale for the arm, the neck disability index (NDI), Odom criteria and postoperative complications. The cervical range of motion (ROM), fusion rate and adjacent segments degeneration were assessed with radiographs.

Results : Significant improvements in arm pain relief and functional outcome were observed in ACDF and HS group. The NDI in the HS group showed better improvement 6 months after surgery than that of the ACDF group. The ACDF group had a lower fusion rate, higher incidence of device related complications and radiological changes in adjacent segments compared with the HS group. The better recovery of cervical ROM was observed in HS group. However, that of the ACDF group was significantly decreased and did not recover.

Conclusion : The HS group was better than the ACDF group in terms of NDI, cervical ROM, fusion rate, incidence of postoperative complications and adjacent segment degeneration.

Key Words : Cervical spondylosis · Arthroplasty · Anterior cervical discectomy fusion · Total disc replacement.

\section{INTRODUCTION}

Cervical spondylosis (CS) is a common pathological condition in elderly patients and is a frequent cause of disability and loss of productivity ${ }^{8,22}$. Surgical options to treat cervical spondylosis include anterior cervical discectomy and fusion or corpectomy (ACDF or ACC), posterior decompression (lami- noplasty or laminectomy and fusion) and the combined anterior and posterior approach. However, in many cases, CS often involves multilevel lesions and surgical treatment can be challenging and complicated in multilevel CS. To date, the most effective and safest surgical treatment for patients with multilevel CS remains controversial. When the anterior approach is employed, multilevel ACDF or ACC are typically used and

- Received : October 17, 2016 •Revised : January 5, 2017 •Accepted : January 31, 2017

- Address for reprints : Sang-Bok Lee, M.D.

Department of Neurosurgery, Uijeongbu St. Mary's Hospital, College of Medicine, The Catholic University of Korea, 271 Cheonbo-ro, Uijeongbu 11765, Korea Tel : +82-31-820-3299, Fax : +82-31-846-3117, E-mail : leesb@catholic.ac.kr

This is an Open Access article distributed under the terms of the Creative Commons Attribution Non-Commercial License (http://creativecommons.org/licenses/by-nc/4.0) which permits unrestricted non-commercial use, distribution, and reproduction in any medium, provided the original work is properly cited. 
Hybrid Surgery with 3-Level Cervical Spondylosis | Jang SR, et al.

these techniques have already been proven to be effective and safe $^{26)}$. The anterior approach is very effective in resolving symptoms and improving nerve function. Most of all, many spine surgeons are familiar with this approach. In spite of these favorable factors, high pseudoarthrosis rate and device related complications are well-known problems and are often observed after multilevel $\mathrm{ACDF}^{2,20,28)}$. Additionally, adjacent segment degeneration (ASD) has been described as a long term complication of ACDF because it alters the normal spinal biomechanics ${ }^{3,4,10)}$. Some studies have reported that 2 level hybrid surgery (HS), consisting of cervical disc replacement (CDR) combined with ACDF, shows favorable clinical and radiological outcomes compared to 2 level fusion surgery ${ }^{24)}$. However, there are only a few studies comparing 3-level ACDF and 3-level HS for the treatment of contiguous 3-level CS that spans more than 2 disc levels.

The purpose of this study was to compare the clinical and radiologic outcomes of patients with 3-level CS who were treated with CDR combined with ACDF (HS group) and 3-level ACDF (ACDF group).

\section{MATERIALS AND METHODS}

\section{Patient populations and indications}

After institutional review board approval was obtained, a retrospective review of 49 patients who underwent surgical treatment for contiguous 3-level cervical spine lesions was performed. From January 2010 to January 2014, 49 patients (34/15 [males/females]) that underwent 3-level anterior cervical spine surgery were included in this study. The mean age was 57.8 years, ranging from 39 to 78 years. The demographic and clinical data for the 49 patients are summarized in Table 1. According to the surgical techniques, these patients were classified into 2 groups : ACDF group and HS group. HS was defined as a CDR combined with ACDF. Nineteen patients in the HS group were compared with 30 patients in the ACDF group. The ACDF group underwent fusion with a cervical plate system (Zephir plate; Medtronic, Memphis, TN, USA). In total disc replacement (TDR) group, 19 patients had 30 arthroplasties using Active-C $\operatorname{disc}^{\circledR}$ (B. Braun, Sheffield, UK) and Baguera $C^{\circledR}$ (Spineart, Paris, France). All surgeries were performed by two surgeons in our institute.

The patient inclusion criteria in both groups were : 1) patients must have cervical radiculopathy and/or myelopathy; 2) cervical spondylosis include degenerative disc disease, degenerative ligamentous disease and/or osteophyte formation and must be confirmed by cervical radiography, computed tomography (CT) and magnetic resonance imaging (MRI); and 3) cervical spine pathologies were 3 consecutive levels between C3 and T1 which had not responded to conservative treatment (medication for at least 6 weeks). Cases with more than 3 levels

Table 1. Demographic data of patients

\begin{tabular}{|c|c|c|c|}
\hline Variables & ACDF group $(n=30)$ & Hybrid group $(n=19)$ & $p$-value \\
\hline Age & $60.2 \pm 14.4(43-78)$ & $53.5 \pm 12.9(39-71)$ & 0.16 \\
\hline Sex ration $(M: F)$ & $21: 9$ & $13: 6$ & 0.90 \\
\hline Symptoms & & & 0.75 \\
\hline Radiculopathy & 25 & 16 & \\
\hline Myelopathy & 5 & 3 & \\
\hline \multirow[t]{2}{*}{ Number of ACDF level } & 3-level ACDF : 30 & 2 CDR with 1 ACDF : 11 & \\
\hline & & 1 CDR with 2 ACDF : 8 & \\
\hline Level of surgery & & & 0.31 \\
\hline$C 3-4-5-6$ & 6 & 3 & \\
\hline$(4-5-6-7$ & 21 & 16 & \\
\hline C5-6-7-T1 & 3 & 0 & \\
\hline Follow up periods & $32.2 \pm 13.1(24-51)$ & $30.5 \pm 18.6(24-41)$ & 0.53 \\
\hline
\end{tabular}

Values are presented as mean \pm standard deviation (range). ACDF : anterior cervical discectomy and fusion, $\mathrm{M}:$ male, F : female, CDR : cervical disc replacement 
were excluded because the number of cases was small. In the HS group, at least one-level must meet the criteria for CDR among the multilevel lesions. According to the degree of degeneration in the cervical spine, fusion or CDR was selected. The degree of degeneration was determined by using preoperative dynamic radiographs, CT or MRI scans. If there were no motion, the presence of instability and severe degeneration, such as facet hypertrophy, ligament flavum hypertrophy and/ or osteophyte formation in target level, ACDF was performed. If the target level met the CDR criteria, CDR was performed. Exclusion criteria included those currently accepted for ACDF or CDR.

\section{Clinical and radiological outcomes evaluations}

The reviewed clinical outcomes were evaluated based on the visual analogue scale (VAS) of the arm, the neck disability index (NDI) and the Odom's criteria ${ }^{15)}$. Pain intensity was rated from 0 to 10 . The NDI scores varied from 0 to 50 . The results were recalculated and expressed on a scale ranging from $0 \%$ (no disability) to $100 \%$ (maximum disability). Clinical outcome evaluation was performed before surgery and the routine postoperative interval was 1, 6, 12, and 24 months.

Preoperative dynamic radiographs, CT scanning and MRI were performed for all the patients. Postoperative dynamic radiographs were evaluated at the interval of $1,6,12$, and 24 months. The cervical ROM was calculated based on the difference in Cobb angles between full flexion and full extension on the lateral radiograph with PACS workstation (Marosis; Marotech, Suncheon, Korea) (Fig. 1). Lordosis was expressed as a negative value and kyphosis was expressed as a positive. We checked the ROM twice and obtained the mean to reduce the error. The radiological change in the adjacent level after surgery was also evaluated. The ASD during the follow up periods was determined as follows : 1) increased or newly developed narrowing of the disc space; 2) new osteophyte formation or enlargement; and 3) new or enlarged calcification of the anterior longitudinal ligament.

Complications were retrospectively reviewed via the medical records of each patient. The complications for all patients were investigated including surgery related complications (soft tissue swelling, infections, hematoma, dysphagia and hoarseness), device/graft-related complications (graft dislodgement, hardware breakage, screw pull out, and graft subsidence) and pseudoarthrosis. Pseudoarthrosis was defined when the fol- lowing conditions were still observed 3 months after surgery : 1) radiolucent line or gap observed between the graft and end plate; 2) motion at the treated level observed on dynamic lateral X-ray views; and 3) bony bridging not observed between the graft and the endplate.

\section{Statistical analysis}

The comparison of group characteristic, functional outcome, complication rate and radiological change of adjacent degeneration between the groups after surgery was performed using Chi-square tests. Radiological values were checked 2 times and the mean values were used for statistical analysis. Continuous variables including NDI and ROM were expressed as mean \pm standard deviation. Independent t-test was used in analysis of clinical and radiological results. All the statistical analysis was performed with SPSS software version 15 (SPSS Inc., Chicago, IL, USA). $p$ values $<0.05$ were considered statistically significant.

\section{RESULTS}

Over 5 years, forty nine patients with 3 consecutive levels of CS were treated with 3-level ACDF or 3-levels HS at our institution. Among 19 patients in HS group, 2-level TDR and 1-level ACDF was performed in 11 patients and 8 patients underwent 1-level TDR and 2-level ACDF. The mean clinical and radiological follow-up period ranged was 42.3 months (range,

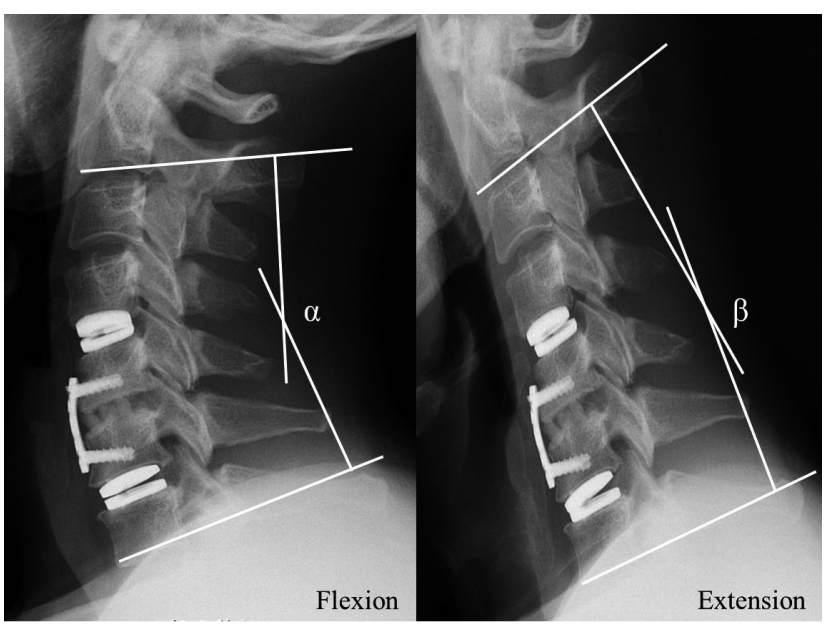

Fig. 1. The cervical ROM is defined as the difference in the Cobb angle between the lateral flexion ( $\mathrm{C} 2-\mathrm{C} 7 \mathrm{Cobb}, \alpha)$ and extension (C2-C7 Cobb, $\beta$ ) view. ROM : range of motion. 
Hybrid Surgery with 3-Level Cervical Spondylosis | Jang SR, et al.

24-51 months). A diagnosis of cervical radiculopathy and/or myelopathy was established in all patients. The male-to-female ratio was $34: 15$ and the mean patient age was 57.8 years (range, 39-78 years). The operation time was investigated in the two groups. The operation time in the ACDF and HS group was $129.4 \pm 25.9$ and $116.5 \pm 29.8$ minutes. No significant difference was observed between the two groups $(p>0.05)$. Clinical and radiological results were summarized in Table 2.

\section{Clinical outcomes}

The mean VAS scores for arm pain in the ACDF group significantly decreased from $6.7 \pm 0.7$ preoperatively to $3.1 \pm 0.6$ in 1 month, $2.8 \pm 0.5$ in 6 months, $2.4 \pm 0.8$ in 12 months, and $1.7 \pm$ 0.5 in 24 months after surgery. The corresponding mean VAS scores for arm pain in the HS group also significantly decreased from $6.5 \pm 0.9$ preoperatively to $2.9 \pm 0.6,2.5 \pm 0.7,2.2 \pm$ 0.9 , and $1.6 \pm 0.6$, respectively. There was no significant difference between the VAS scores for arm pain between both groups at the last follow up ( $p>0.05)$ (Fig. 2).

Regarding the NDI score, the mean NDI score in the ACDF group significantly improved from $53.6 \pm 9.3 \%$ upon admission to $33.9 \pm 4.3 \%$ after 1 month, $31.9 \pm 3.2 \%$ after 6 months, $29.6 \pm 4.9 \%$ after 12 months, and $28.0 \pm 3.8 \%$ at 24 months $(p<0.05)$. For the HS group, the corresponding mean NDI score significantly improved from $52.7 \pm 7.3 \%$ to $32.7 \pm 3.7 \%$, $25.1 \pm 2.9 \%, 23.6 \pm 2.6 \%$, and $22.3 \pm 3.4 \%$, respectively $(p<0.05)$. The HS group demonstrated better NDI relief than the ACDF group 6 months after surgery ( $p>0.05$ ) (Fig. 3).

According to the Odom's criteria, for the ACDF group, clinical outcomes were excellent in 5 patients, good in 19, fair in 4 and poor in 2. The corresponding Odom criteria for the HS group were as follows: excellent in 6 patients, good in 12, fair in 1 and poor in 0 . There were significant functional improvements in both groups and no significant differences were observed between both groups ( $p>0.05)$.

\section{Radiologic evaluation}

The radiological outcomes were analyzed with the ROM of C2-C7 and were compared between the ACDF and HS groups. Fig. 4 shows the changes in the ROM for the cervical

Table 2. Clinical and radiological results between ACDF group and HS group

\begin{tabular}{|c|c|c|c|}
\hline & $\begin{array}{l}\text { ACDF group } \\
\quad(n=30)\end{array}$ & $\begin{array}{l}\text { HS group } \\
(n=19)\end{array}$ & $\begin{array}{c}p \text {-value } \\
\text { between groups }\end{array}$ \\
\hline Operation time (minutes) & $129.4 \pm 25.9$ & $116.5 \pm 29.8$ & 0.81 \\
\hline \multicolumn{4}{|l|}{ VAS (arm) } \\
\hline Preoperative & $6.7 \pm 0.7$ & $6.5 \pm 0.9$ & 0.68 \\
\hline Postoperative at the last follow up & $1.7 \pm 0.5$ & $1.6 \pm 0.6$ & 0.77 \\
\hline$p$-value within group & 0.00 & 0.00 & \\
\hline \multicolumn{4}{|l|}{ NDI (\%) } \\
\hline Preoperative & $53.6 \pm 9.3$ & $52.7 \pm 7.3$ & 0.73 \\
\hline Postoperative at the last follow up & $28.0 \pm 3.8$ & $22.3 \pm 3.4$ & 0.02 \\
\hline$p$-value within group & 0.00 & 0.00 & \\
\hline Odom's criteria at last follow up & & & 0.86 \\
\hline Excellent & 5 & 6 & \\
\hline Good & 19 & 12 & \\
\hline Fair & 4 & 1 & \\
\hline Poor & 2 & 0 & \\
\hline \multicolumn{4}{|l|}{ ROM for C2-C7 (degree) } \\
\hline Preoperative & $54.2 \pm 10.2$ & $53.5 \pm 7.0$ & 0.69 \\
\hline Postoperative at the last follow up & $32.4 \pm 3.5$ & $41.1 \pm 8.3$ & 0.00 \\
\hline$p$-value within group & 0.00 & 0.00 & \\
\hline
\end{tabular}

ACDF : anterior cervical discectomy and fusion, HS : hybrid surgery, VAS : visual analogue scale, NDI : neck disability index, ROM : range of motion 


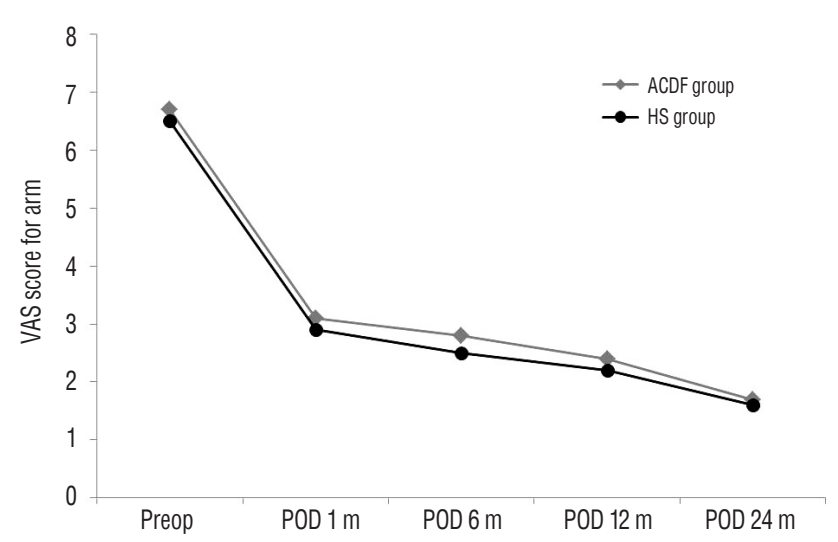

Fig. 2. The VAS score for arm pain was significantly decreased in both groups. No difference was observed between the two groups at the last follow up. VAS : visual analogue scale, ACDF : anterior cervical discectomy and fusion, $\mathrm{HS}$ : hybrid surgery, POD : post operation day.

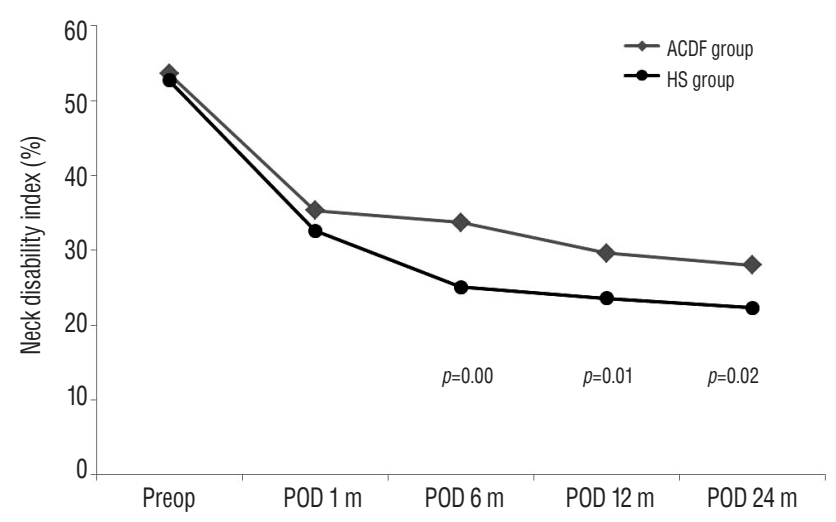

Fig. 3. The HS group shows better NDI relief than the ACDF group 6 months after surgery $(p<0.05)$. NDI : neck disability index, ACDF : anterior cervical discectomy and fusion, HS : hybrid surgery, POD : post operation day.

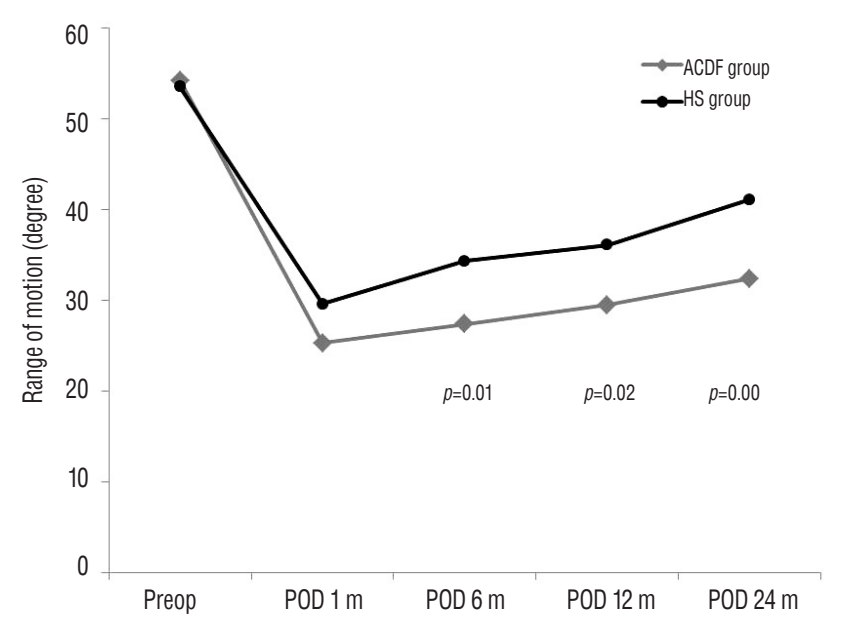

Fig. 4. The cervical ROM of the HS group showed faster recovery than that of the ACDF group. ROM : range of motion, HS : hybrid surgery, ACDF : anterior cervical discectomy and fusion, POD : post operation day. spine over the follow up periods. The ROM for $\mathrm{C} 2-\mathrm{C} 7$ in the ACDF group was significantly decreased from $54.2^{\circ} \pm 10.2^{\circ}$ preoperatively to $25.3^{\circ} \pm 4.3^{\circ}$ in 1 month, $27.4^{\circ} \pm 3.6^{\circ}$ in 6 months, $29.5^{\circ} \pm 2.3^{\circ}$ in 12 months, and $32.4^{\circ} \pm 3.5^{\circ}$ at the last follow up $(p<0.05)$. In the HS group, the corresponding cervical ROM also significantly decreased from $53.5^{\circ} \pm 7.0^{\circ}$ preoperatively to $29.6^{\circ} \pm 7.3^{\circ}, 34.3^{\circ} \pm 6.1^{\circ}, 36.1^{\circ} \pm 6.7^{\circ}$, and $41.1^{\circ} \pm$ $8.3^{\circ}$ at the last follow up $(p<0.05)$. Comparing the ROM between the two groups, significant differences in $\mathrm{ROM}$ for $\mathrm{C} 2-$ C7 were observed 6 months after surgery (Fig. 4).

The incidence of ASD was analyzed according to the change in postoperative radiological imaging. Table 3 summarizes the radiological changes in adjacent segments in both groups at the last follow up after surgery. A total of 11 (36.6\%) patients in the ACDF group experienced ASD during the follow up periods. In contrast, 2 (10.5\%) patients with ASD were observed in the HS group. Radiographic ASD changes in the ACDF group were observed more frequently than in the HS group $(p<0.05)$. Among thirteen ASD patients, none required second surgery due to symptomatic ASD.

The fusion rates in the ACDF group and the HS group were $70 \%$ (21 patients) and 94.7\% (18 patients) at the last follow up. Significant difference was observed between both groups $(p<0.05)$.

\section{Complications}

Postoperative dysphagia and device-related complications (plate migration, screw pull out, screw breakage and graft dislodgment) were more common in the ACDF group than the HS group. In the ACDF group, a total of 16 (53.3\%) postoperative complications including dysphagia (6 cases, $20 \%)$, plate migration (5 cases, $16.6 \%$ ), screw pull out ( 2 cases, $6.6 \%)$, screw breakage (1 case, $3.3 \%$ ), and graft dislodgment (2 cases, $6.6 \%)$ occurred during the follow up periods. Among these patients, 3 patients required additional surgery for posterior screw fixation. In the HS group, postoperative complications including dysphagia (1 case, 5.2\%) and plate migration (1 case, $5.2 \%)$ occurred during the follow up periods. No other complications were observed in the HS group. There was a significant difference in the incidence of device-related complications between the two groups $(p<0.05)$. 
Hybrid Surgery with 3-Level Cervical Spondylosis | Jang SR, et al.

Table 3. Radiological changes of adjacent segment after surgery

\begin{tabular}{lcc}
\hline & ACDF group $(\mathbf{n}=\mathbf{3 0})$ & HS group $(\mathbf{n}=\mathbf{1 9 )}$ \\
\hline Increased disc space narrowing & $3(10)$ & $1(5.2)$ \\
New osteophyte formation or enlargement & $7(23.3)$ & $1(5.2)$ \\
New or enlargement of calcification of ALL & $1(3.3)$ & $0(0)$ \\
Total of new radiological changes & $11(36.6)$ & $2(10.5)$ \\
\hline
\end{tabular}

Values are presented as number (\%). ACDF : anterior cervical discectomy and fusion, HS : hybrid surgery, ALL : anterior longitudinal ligament

\section{DISCUSSION}

In the present study, we evaluated the efficacy and safety of HS in 3-level CS compared to 3-level ACDF. Multilevel ACDF has some problems including the device related complications and high pseudoarthrosis rate even when an anterior plate is used $^{20,28)}$. More importantly, it is possible that the consecutive 3-level fusion may increase excessive motion and accentuate the degeneration of the remaining mobile segment compare to the single level fusion ${ }^{7,16)}$.

CDR was devised to compensate for the disadvantages of $\mathrm{ACDF}^{9,17-19,21)}$. Recently, ACDF is gradually being replaced by CDR as the surgical option for managing single level cervical disease. However, Auerbach et al. ${ }^{1)}$ reported that only $43 \%$ of patients with cervical spine disease met the CDR criteria, or if the indications were expanded to include the treatment of ASD, the percentage of qualifiers rose to $47 \%$.

In multilevel CS, there are limited studies about the efficacy of multilevel CDR and the biomechanics that affect the normal cervical spine motion. In order to overcome these problems related to multilevel ACDF or CDR, HS was devised. The basic concept of HS is that not all affected disc levels show the same degree of degeneration. Therefore, it is reasonable to tailor the most suitable procedure according to the status of the affected levels.

In the present study, comparison of the clinical and radiological results of ACDF versus the HS group with at least 2-year follow-up is presented. The operation time for the HS group was similar to that for the ACDF group. The clinical outcomes including VAS for arm pain, NDI and Odom's criteria were significantly improved postoperatively compared to the preoperative status in all patient regardless to surgical methods. Consequently, both surgeries are effective for reducing radicular pain and restoring function. We speculate that this was the result of nerve root decompression rather than the specific technique - ACDF versus hybrid surgery - used. Particularly, NDI in the HS group showed better improvement than in the ACDF group, which was consistent with previous studies ${ }^{13,21)}$. Regarding the radiological results, cervical ROM significantly decreased in both groups after surgery compared to the preoperative status. In the ACDF group, it was more significantly decreased than in the HS group. However, the ROM decrease in the HS group was limited to 6 months after surgery and gradually recovered and maintained during the follow up periods. Shin et al. ${ }^{24)}$ reported that HS in 2-level CSD is superior to 2-level ACDF in terms of clinical and radiological outcomes. Kang et al. ${ }^{8)}$ also reported that the combination of 2-level TDR with 1 level ACDF is comparable to 2-level ACCF in 3-level CSD. Our results are very similar to those of previous studies in that the 3-level HS group demonstrated better neck pain relief and radiological outcomes than the 3-level ACDF group. This may be associated with the preservation of the range of motion at the treated level and may be the basis for better clinical and radiological outcomes.

Regarding the complications, our study showed a higher incidence of device related complications including plate migration, screw pull out, screw breakage and graft dislodgement in the ACDF group than the HS group. This means that anterior plating alone lacks sufficient fixation power to immobilize the multilevel anterior cervical fixation. Some surgeons recommend combined anterior and posterior fixations for patients with multilevel CS to decrease these complications ${ }^{11,14,23,25,27)}$. In our cases, additional posterior fixations were needed and 3 cases of posterior screw fixation were performed in the ACDF group during the follow up periods. However, additional posterior surgery runs the risk of surgical morbidity and additional expenses due to the long operative time and hospital stay. It may also lead to unnecessary postoperative neck pain for the patients. We suppose HS may reduce the compensatory movement or intradiscal pressure on adjacent segments. Ad- 
ditionally, HS may have a smaller hardware/graft-spine interface than 3-level fusion. Theoretically, it will help to decrease the stress to the graft and plate and reduce device related complications.

Postoperative radiologic changes of adjacent levels in both groups were also investigated. Our results showed that ASD changes were more common in the ACDF group than in the HS group, in close agreement with previous studies on the incidence of ASD after fusion ${ }^{5,6,12,18)}$. Symptomatic ASD were not observed and no second revision surgery was needed during the follow up periods. We concluded that 2 years of follow up was not enough to observe the radiological changes in adjacent levels to convert to the symptomatic adjacent segment disease. A longer follow-up period is needed to evaluate the incidence of adjacent segment disease after multilevel ACDF.

This study has some limitations. First, this clinical study is a retrospective cases series. Second, in HS group, the surgical method and types of artificial discs are not homogeneous. Thirds, the number of patients was small and the follow up period was too short to draw a firm conclusion. A randomized controlled trial will be needed to evaluate these procedures in the future.

\section{CONCLUSION}

This result indicated that 3-level HS is an effective and safe procedure compared to 3-level ACDF in terms of NDI, fusion rate, restoration of ROM, reducing adjacent segment degeneration and complication rate. The selection of these surgical options must be considered first according to the degree of degeneration at each level and the location of the pathology.

\section{References}

1. Auerbach JD, Jones KJ, Fras $\mathrm{Cl}$, Balderston JR, Rushton $\mathrm{SA}$, Chin KR : The prevalence of indications and contraindications to cervical total disc replacement. Spine J $8:$ 711-716, 2008

2. DiAngelo DJ, Foley KT, Vossel KA, Rampersaud YR, Jansen TH : Anterior cervical plating reverses load transfer through multilevel strut-grafts. Spine (Phila Pa 1976) 25 : 783-795, 2000

3. Eck JC, Humphreys SC, Lim TH, Jeong ST, Kim JG, Hodges SD, et al. : Biomechanical study on the effect of cervical spine fusion on adjacentlevel intradiscal pressure and segmental motion. Spine (Phila Pa
1976) $27: 2431-2434,2002$

4. Fuller DA, Kirkpatrick JS, Emery SE, Wilber RG, Davy DT : A kinematic study of the cervical spine before and after segmental arthrodesis. Spine (Phila Pa 1976) 23 : 1649-1656, 1998

5. Goffin J, Geusens E, Vantomme N, Quintens E, Waerzeggers Y, Depreitere $B$, et al. : Long-term follow-up after interbody fusion of the cervical spine. J Spinal Disord Tech 17 : 79-85, 2004

6. Hunter $L Y$, Braunstein EM, Bailey RW : Radiographic changes following anterior cervical fusion. Spine (Phila Pa 1976) 5 : 399-401, 1980

7. Jacobs WC, Willems $P C$, van Limbeek J, Bartels $R$, Pavlov $P$, Anderson $P G$, et al. : Single or double-level anterior interbody fusion techniques for cervical degenerative disc disease. Cochrane Database Syst Rev (1) : CD004958, 2004

8. Kang L, Lin D, Ding Z, Liang B, Lian K : Artificial disk replacement combined with midlevel ACDF versus multilevel fusion for cervical disk disease involving 3 levels. Orthopedics 36 : e88-e94, 2013

9. Kim HJ, Kelly MP, Ely CG, Dettori JR, Riew KD : The risk of adjacentlevel ossification development after surgery in the cervical spine: are there factors that affect the risk? A systematic review. Spine (Phila Pa 1976) 37(22 Suppl) : S65-S74, 2012

10. Matsunaga S, Kabayama S, Yamamoto T, Yone K, Sakou T, Nakanishi K : Strain on intervertebral discs after anterior cervical decompression and fusion. Spine (Phila Pa 1976) 24 : 670-675, 1999

11. McAfee PC, Bohlman HH, Ducker TB, Zeidman SM, Goldstein JA : One stage anterior cervical decompression and posterior stabilization. $A$ study of one hundred patients with a minimum of two years of followup. J Bone Joint Surg Am 77 : 1791-1800, 1995

12. McGrory BJ, Klassen RA : Arthrodesis of the cervical spine for fractures and dislocations in children and adolescents. A long-term follow-up study. J Bone Joint Surg Am 76 : 1606-1616, 1994

13. Mummaneni PV, Burkus JK, Haid RW, Traynelis VC, Zdeblick TA : Clinical and radiographic analysis of cervical disc arthroplasty compared with allograft fusion: a randomized controlled clinical trial. J Neurosurg Spine 6 : 198-209, 2007

14. O'Shaughnessy BA, Liu JC, Hsieh PC, Koski TR, Ganju A, Ondra SL : Surgical treatment of fixed cervical kyphosis with myelopathy. Spine (Phila Pa 1976) $33: 771-778,2008$

15. Odom GL, Finney W, Woodhall B : Cervical disc lesions. JAMA 166 : 23-28, 1958

16. Park DH, Ramakrishnan $\mathrm{P}$, Cho TH, Lorenz E, Eck JC, Humphreys SC, et al. : Effect of lower two-level anterior cervical fusion on the superior adjacent level. J Neurosurg Spine 7 : 336-340, 2007

17. Pickett GE, Rouleau JP, Duggal $N$ : Kinematic analysis of the cervica spine following implantation of an artificial cervical disc. Spine (Phila Pa 1976) 30 : 1949-1954, 2005

18. Robertson JT, Papadopoulos SM, Traynelis VC : Assessment of adjacentsegment disease in patients treated with cervical fusion or arthroplasty: a prospective 2-year study. J Neurosurg Spine 3 : 417-423, 2005

19. Sasso RC, Anderson PA, Riew KD, Heller JG : Results of cervical arthroplasty compared with anterior discectomy and fusion: four-year clinical outcomes in a prospective, randomized controlled trial. Orthopedics 
Hybrid Surgery with 3-Level Cervical Spondylosis | Jang SR, et al.

$34: 889,2011$

20. Sasso RC, Ruggiero RA Jr, Reilly TM, Hall PV : Early reconstruction failures after multilevel cervical corpectomy. Spine (Phila Pa 1976) 28 : 140-142, 2003

21. Sasso RC, Smucker JD, Hacker RJ, Heller JG : Artificial disc versus fusion: a prospective, randomized study with 2-year follow-up on 99 patients. Spine (Phila Pa 1976) 32 : 2933-2940; discussion 2941-2942, 2007

22. Schoenfeld AJ, George AA, Bader JO, Caram PM Jr : Incidence and epidemiology of cervical radiculopathy in the United States military: 2000 to 2009. J Spinal Disord Tech 25 : 17-22, 2012

23. Schultz KD Jr, McLaughlin MR, Haid RW Jr, Comey CH, Rodts GE Jr, Alexander $\mathrm{J}$ : Single-stage anterior-posterior decompression and stabilization for complex cervical spine disorders. J Neurosurg 93(2 Suppl) : 214-221, 2000

24. Shin DA, Yi S, Yoon DH, Kim KN, Shin HC : Artificial disc replacement combined with fusion versus two-level fusion in cervical two-level disc disease. Spine (Phila Pa 1976) 34 : 1153-1159; discussion 1160-1151 2009

25. Song KJ, Song JS, Kim DY, Shim DG, Lee KB : Efficacy of combined anteroposterior fusion with no plate versus anterior fusion alone with cage and plate for multilevel degenerative cervical disease. Spine J 14 : 598 603, 2014

26. Uribe JS, Sangala JR, Duckworth EA, Vale FL : Comparison between anterior cervical discectomy fusion and cervical corpectomy fusion using titanium cages for reconstruction: analysis of outcome and long-term follow-up. Eur Spine J 18 : 654-662, 2009

27. Vanichkachorn JS, Vaccaro AR, Silveri CP, Albert TJ : Anterior junctional plate in the cervical spine. Spine (Phila Pa 1976) 23 : 2462-2467, 1998

28. Zdeblick TA, Hughes SS, Riew KD, Bohlman HH : Failed anterior cervical discectomy and arthrodesis. Analysis and treatment of thirty-five patients. J Bone Joint Surg Am 79 : 523-532, 1997 